\title{
PREVALENCE AND EVALUATION OF REFRACTIVE ERRORS IN CHILDREN BETWEEN THE AGES 10-15 YEARS IN RIMS TEACHING HOSPITAL RAICHUR
}

H. Siddesh Kumar ${ }^{1}$, Srividya $\mathrm{R}^{* 2}$.

${ }^{1}$ Associate professor in dept. of ophthalmology, RIMS, Raichur, Karnataka, India.

*2 Junior resident in dept. of ophthalmology, RIMS, Raichur, Karnataka, India.

\section{ABSTRACT}

Purpose: Prevalence, diagnosis and treatment of refractive error is relativity simple and easiest way to reduce impaired vision, population-based data in children are not sufficiently available for India. In view of importance of detecting the refractive error in children an effort is going to be made in this study. To find out the extent of problem of refractive errors among children in Raichur.

Materials and Methods: the prospective study was conducted with 100 number 10-15 years children from the Raichur. All the children were examined with visual acuity by snellen's chart, Examination of anterior and posterior segment, Retinoscope, trail set and cycloplegic refraction followed by subjective correction will be done.

Results: The prevalence of Refractive error in the 10-15 years children was found to be $11 \%$, higher in 15 years (3\%), more in girls (6\%) and in urban area children had more prevalence (7\%). Myopia was the commonest type of refractive error in this study which constitutes $55 \%$, Astigmatism $27 \%$ and $18 \%$ of hypermetropia was seen in the 10-15yrs children.

Conclusion: Most of the children are unaware of Refractive error, so screening of children is very important. Parents have to take the responsibility of this screening for vision error and they should monitor the their vision vial watching tv, reading books. The screening system should be yearly at least 3 time a year to every child especially 14-15 years student.

KEY WORDS: Astigmatism, Hypermetropia, Myopia, Refractive error.

Address for correspondence: Dr. Srividya R, Junior resident in dept. of ophthalmology, RIMS, Raichur, Karnataka, India. E-Mail: drsiddesh@gmail.com, srividyador@gmail.com

\begin{tabular}{|c|c|c|}
\hline \multicolumn{3}{|c|}{ Online Access and Article Informtaion } \\
\hline \multirow{2}{*}{$\begin{array}{c}\text { Quick Response code } \\
\text { DOI: } 10.16965 / \text { ijims.2019.112 }\end{array}$} & \multicolumn{2}{|c|}{$\begin{array}{l}\text { International/Journal of Integrative Medical Sciences } \\
\text { ISSN (P): } 2394 \text { - 6318. ISSN (E): } 2394-4137 \\
\text { www.imedsciences.com }\end{array}$} \\
\hline & $\begin{array}{l}\text { Received: 11-05-2019 } \\
\text { Reviewed: 11-05-2019 }\end{array}$ & $\begin{array}{l}\text { Accepted: 21-05-2019 } \\
\text { Published: 20-07-2019 }\end{array}$ \\
\hline Source of Funding: Self & \multicolumn{2}{|c|}{ Conflicts of interest: None } \\
\hline
\end{tabular}

\section{INTRODUCTION}

In school age children has 20/20 visual acuity, ocular muscular control peripheral vision and colour discrimination are fully developed [1]. Poor vision can affect the performance in the studies and extra cultural activities, it also could adversely affect the personality development of children. Visual impairment can be caused by a number of genetic and prenatal or postnatal conditions like perinatal infections (herpes Chlamydia, gonococci, rubella, syphilis etc), sickle cell disease, and retinoblastoma [1].

There are 180 million visually disabled people in the world out of whom 45 million people are blind. 60\% from India, china and Africa [2], India alone has 12 million blind people. $80 \%$ of blindness is due to avoidable causes [3]. So, WHO launched a global initiative VISION 2020RIGHT TO SIGHT, on the 18th of February 1999, to eliminate avoidable blindness by the year 2020 [4]. In context of vision 2020, the priorities for action to reduce childhood blindness in 
India are refractive error, cataract related amblyopia and corneal diseases [5]. The preventive and interventional measures identified for tackling this problem is school age screening programme for detection and correction of refractive errors.

Refractive error is an optical defect intrersic to the eye, which prevents light from being brought to a single point focus on retina, thus reducing normal vision and the second most common blindness in the world and also in India [6]. There are three basic abnormalities of refraction that occur in the eye (1) Myopia (2) Hypermetropia and (3) Astigmatism. Myopia is a condition in which light rays come in to focus in front of the retina. Hypermetropia is the condition in which the focus point falls behind the eye and consequently the image that falls on retina. Astigmatism is the condition in which rays of light are not bent equally by the cornea in all direction so that the point of focus is not attained [7].

According to WHO statistics, worldwide, there are 1.5 million children are blind, 2, 70,000 live in India. The overall prevalence of refractive errors is $44.1 \%$, about $5-15 \%$ of children are considered to have refractive errors [8]. In India 13\% of $10-15$ years [9], $20 \%$ of 16 years age group children develop refractive error [10], In India $6-7 \%$ of children in the age group of $10-15$ years have refractive errors affecting their learning at school [11]. A cross sectional study conducted in the Kolkata, 5-10 years school children out of 2317 students, 585 (25.11\%) were suffering from refractive errors [12]. According to the Andra Pradesh eye disease study conducted in the Hyderabad with 2522 subject 10-15 years age group the prevalence of myopia was $4.44 \%$ [13]. And in another study from Karnataka, the prevalence rate of refractive errors among school children about 9-10\%. Myopia accounts for the highest i.e., 9.97\% Hypermetropia accounts for $5.3 \%$ and astigmatism accounts for $1.18 \%$. About $40 \%$ of Indian population is in the age group of 6-10 years [8]. Proper screening and referral, as well as notification to parents of the existing condition are essential to the educational to the educational and socialisation of school age children.
Prevalence, diagnosis and treatment of refractive error is relativity simple and is the easiest way to reduce impaired vision. Children are easily accessible group in population who could be easily identified and treated. Population based data concerning prevalence on refractive errors in children are not sufficiently available for India. There have been repeator of refractive errors for population of other countries but only little has been reported for India population. In view of importance of detecting the refractive error in children an effort is going to be made in this study. To find out the extent of problem of refractive errors among children in Raichur.

\section{MATERIALS AND METHODS}

After obtaining Institutional Ethical clearance the prospective study was conducted with urban and rural area practice are of Ophthalmology department at RIMS teaching hospital Raichur, with 100 number $10-15$ years children from the Raichur were included in the study. The children with corneal opacities, Lens opacities, Retinal pathology, optic nerve disorder were excluded from the study. All the children were examined with visual acuity by snellen's chart, Examination of anterior and posterior segment, Retinoscope, trail set and cycloplegic refraction followed by subjective correction will be done. Myopia is the measured objective refraction is less than or equal to - $0.5 \mathrm{D}$ spherical equivalent diopters in one or both eyes, Hypermetropia is the measured objective refraction is less than or equal to $+0.5 \mathrm{D}$ spherical equivalent diopters in one or both eyes, and Astigmatism is visually significant if $\geq+/-0.5 \mathrm{D}$. After evaluation, all findings will be entered in excel spreadsheet and analysed by using SPSS 17 version.

\section{RESULTS}

Table 1: Showing the age and sex distribution in the children.

\begin{tabular}{|c|c|c|c|c|c|c|}
\hline \multirow{2}{*}{ AGE } & \multicolumn{2}{|c|}{ BOYS } & \multicolumn{2}{c|}{ GIRLS } & \multicolumn{2}{c|}{ Total } \\
\cline { 2 - 7 } & Number & $\%$ & Number & $\%$ & Number & $\%$ \\
\hline 10years & 9 & 9 & 7 & 7 & 16 & 16 \\
\hline 11years & 9 & 9 & 7 & 7 & 16 & 16 \\
\hline 12years & 9 & 9 & 7 & 7 & 16 & 16 \\
\hline 13years & 9 & 9 & 7 & 7 & 16 & 16 \\
\hline 14years & 9 & 9 & 9 & 9 & 18 & 18 \\
\hline 15years & 9 & 9 & 9 & 9 & 18 & 18 \\
\hline Total & 54 & 54 & 46 & 46 & 100 & 100 \\
\hline
\end{tabular}


Fig. 1: Showing the Region Distribution of Children. Region



Table 2: Showing the vision of the children.

\begin{tabular}{|c|c|c|}
\hline Vision & Number & $\%$ \\
\hline $6 / 6$ & 89 & 89 \\
\hline $6 / 9$ & 5 & 5 \\
\hline $6 / 12$ & 3 & 3 \\
\hline $6 / 18$ & 2 & 2 \\
\hline $6 / 24$ & 1 & 1 \\
\hline $6 / 36$ & 0 & 0 \\
\hline $6 / 60$ & 0 & 0 \\
\hline Total & 100 & 100 \\
\hline
\end{tabular}

Table 3: Showing the Refractive errors on age basis in the children.

\begin{tabular}{|c|c|c|c|c|c|c|}
\hline \multirow{2}{*}{ AGE } & \multicolumn{3}{|c|}{ Refractive errors } & \multicolumn{3}{c|}{ Total } \\
\cline { 2 - 6 } & \multicolumn{2}{|c|}{ Present } & \multicolumn{2}{c|}{ Absent } & \multicolumn{2}{c|}{} \\
\cline { 2 - 6 } & Number & $\%$ & Number & $\%$ & Number & $\%$ \\
\hline 10years & 1 & 1 & 15 & 15 & 16 & 16 \\
\hline 11years & 2 & 2 & 14 & 14 & 16 & 16 \\
\hline 12years & 1 & 1 & 15 & 15 & 16 & 16 \\
\hline 13years & 2 & 2 & 14 & 14 & 16 & 16 \\
\hline 14years & 2 & 2 & 16 & 16 & 18 & 18 \\
\hline 15years & 3 & 3 & 15 & 15 & 18 & 18 \\
\hline Total & 11 & 11 & 89 & 89 & 100 & 100 \\
\hline
\end{tabular}

Table 4: Showing the Refractive errors on gender and region basis in the children.

\begin{tabular}{|c|c|c|c|c|c|c|}
\hline & \multicolumn{3}{|c|}{ Refractive errors } & \multicolumn{2}{c|}{ Total } \\
\hline \multirow{2}{*}{ AGE } & \multicolumn{2}{|c|}{ Present (11 N0.) } & \multicolumn{2}{|c|}{ Absent (89 N0.) } & \multicolumn{2}{c|}{ Present } \\
\cline { 2 - 6 } & Number & $\%$ & Number & $\%$ & Number & $\%$ \\
\hline BOYS & 5 & 5 & 49 & 49 & & \multirow{2}{*}{11} \\
\hline GIRLS & 6 & 6 & 40 & 40 & & \\
\hline URBAN & 7 & 7 & 38 & 38 & \multirow{2}{*}{11} & 11 \\
\hline RURAL & 4 & 4 & 51 & 51 & & \\
\hline
\end{tabular}

Table 5: Showing the Power in Diopters in having the Refractive errors children.

\begin{tabular}{|c|c|c|c|c|}
\hline \multirow{2}{*}{$\begin{array}{c}\text { Power in } \\
\text { Diopters }\end{array}$} & \multicolumn{2}{|c|}{ Right eye } & \multicolumn{2}{c|}{ Left eye } \\
\cline { 2 - 5 } & Number & $\%$ & Number & $\%$ \\
\hline$\leq-0.5$ & 5 & 45.45 & 6 & 54.55 \\
\hline$\leq+0.5$ & 2 & 18.18 & 2 & 18.18 \\
\hline$\geq \pm \mathbf{0 . 5}$ & 4 & 36.36 & 3 & 27.27 \\
\hline
\end{tabular}

Fig. 2: Showing the Power in Diopters in having the Refractive errors children.

Type of Refractive errors



\section{DISCUSSION}

The prospective study was conducted in with urban and rural area practice are of Ophthalmology department at RIMS teaching hospital, Raichur, with 100 number $10-15$ years children and to assess the prevalence and evaluation of refractive errors.

The most important cause of vision impairment in the current study was refractive error, A Total no. of 100 students were examined and included out of which $55 \%$ Rural and $45 \%$ urban area children. The study group had $54 \%$ boys and $46 \%$ girls. $10 y r s-16 \% 11 y r s-16 \%, 12 y r s-16 \%, 13 y r s-$ $16 \%, 14 \mathrm{yrs}-18 \%$ and $15 y \mathrm{rs}-18 \%$ of children were present. All the children were screened for the defective vision with help of Snellen's chart and $11(11 \%)$ children had difficulty in the reading that English and kanda charts from the distance of $6 \mathrm{~cm}$. The prevalence of Refractive error in the $10-15$ years children was found to be $11 \%$. Higher prevalence was seen in the age group of 15 years (3\%). The prevalence of refractive error was more in girls (6\%) than boy (5\%). And in case of region urban area children had more prevalence (7\%) than rural area (4\%).

Which is comparable with studies done Ramachandra K et al. also found the prevalence of refractive error was 10\% [14], Kumar KS et al. found Prevalence of refractive error was $29.14 \%$ in 5-15 years among school-going children of Imphal, Manipur [15]. Kannan U et al. screened 6-12 years schoolchildren refractive error was significantly more in urban (17.5\%) than in the rural area (12\%) [16]. In Dibrugarh Town, Assam, $8.8 \%$ of the study population had refractive error, boys (51\%) more than girls (49\%) [17]. Jabalpur district of Madhya Pradesh, found 4.5\% refractory problems in the age group of 5-15 years. Refractive error was 3.5 times more 
present in males when compared with female subjects. $44.44 \%$ parental history of refractive problems was observed [18].

The majority of the children ( $45.45 \%$ and $54.55 \%)$ had $\mathrm{d}-\mathrm{-}-0.5$ Power in Diopters in the right and left eye. And very few children $(18.18 \%$ and 18.18\%) had $d-+0.5$ Power in Diopters in the right and left eye respectively. Myopia was the commonest type of refractive error. It constitutes $55 \%$ of the refractive error. Astigmatism was seen in $27 \%$ and $18 \%$ of hypermetropia was seen in the 10-15yrs children from urban and rural area of Raichur area. at Bangalore by Sandip Das S et al. found $9.5 \%$ myopia, $2.60 \%$ hypermetropia, $0.47 \%$ astigmatism. Myopia was also more in female similarly greater proportion was noted in private schools [19]. In Dibrugarh Town, Assam, Myopia (7.17\%) was the most common refractive error followed by astigmatism $(2.17 \%)$ and hypermetropia (1.50\%) [17]. Kannan U et al. found Myopia (14.6\%) was the common refractive error in rural and urban children and the risk factors studied, duration of watching television (TV), distance from which TV was watched, duration of computer/video/mobile games, and the duration of play outside had a statistically significant association to the prevalence of refractive error [16].

These data show that vision screening in children in developing countries is useful in early detection of refractive errors and thereby prevent development of amblyopia and visual disability. These data support the assumption that vision screening of children in the developing countries could be useful in the detecting correctable causes of decreased vision, especially refractive errors and in minimizing the long-term vision disability. Most of the children are unaware of Refractive error, so screening of school going age children is very important. In spite of government, parents have to take the responsibility of this screening for vision error and they should monitor the student in the home their vision at watching tv time and reading books time. The screening system should be yearly at least 3 time a year to every school going children especially 14-15 years student.

\section{REFERENCES}

[1]. Sathya Guptha. Text book of paediatrcs. 1st Edition. New Delhi. New age International limited; 1996 .p. 610.

[2]. Chatterjee pr, Roy Chaudhri A, Datta H - Community eye health Journal Indian medical assoc.1999; 97:297-8.

[3]. W.H.O.Data on blindness throughout the world. W.H.O. chronicle 1979;33:718-275.

[4]. World health organization. Global initiative for the elimination of avoidable blindness. Geneva, WHO,1997:61. and WHO preventing blindness in children: report of scientific meeting. Geneva, WHO,2000: 77.

[5]. R. Dandona, L. Dandona. Childhood blindness in India: a population based perspective. $\mathrm{Br} J$ Ophthalmol 2003;87:263-5.

[6]. Rotsos T, Grigoriou D, Kokkolaki A. Children the most valuable natural resource. Dove press Journal. 2009;3(1):429-31

[7]. Viswanathan J \&Desai A.B. Achar's Text book paediatrics. $3^{\text {rd }}$ edition. New Delhi. Orient Hongman private limited; 2007:785.

[8]. Raju P, Ramesh S Ve, Arvind H, George R, Baskaran $M$, Pradeep GP, et al . Prevalence of refractive errors in a rural South Indian population. Invest Ophthalmol Vis Sci 2004;45:4268-72.

[9]. Limburg $\mathrm{H}$ : cost effective screening of school children for refractive errors, W.H.Forum 1995;16:1738.

[10]. Goswmi A, Ahmead E, Shaha PL, Roy IS: An epidemiological pattern of cases of refractive error. JIMA.1979;72(10):227-8.

[11]. Government of India (2004), Annual report 20032004, ministry of health and family welfare, New Delhi.

[12]. Das A, Dutta H. Refractive errors among primary school children in Kolkata. Indian Medical Association. 2005;105(4):169-72.

[13].Dandona R, Dandona L, Srinivas M, Giridhar P, McCarty CA, Rao GN. Population-based assessment of refractive error in India: the Andhra Pradesh eye disease study. Clin Exp Ophthalmol. 2002;30(2):84-93.

[14]. Ramachandra K, Gilyaru S, Eregowda A, Yathiraja S. Prevalence of refractive error and the eye morbidity in school children in Bangalore, India. Int J Contemp Pediatr 2016;3:138-41.

[15]. Kumar KS, Akoijam BS. Prevalence of refractive error among school-going children of Imphal, Manipur. Int J Med Sci Public Health. 2016;5:13648.

[16]. Kannan U, Rajendiran A, Yeraballi D, Shanmugavel $\mathrm{K}$, John NA, Rene S. Refractive error and associated risk factors in 6-12 years schoolchildren. Natl J Physiol Pharm Pharmacol. 2016;6(6):554-8. 
[17]. Mehzabeen Rahman, Bhanu Devi, J.J.Kuli, Gourangie Gogoi. A Study on The Refractive Status of School Going Children Aged Between 10 To 15 Years In Dibrugarh Town, Assam, India. IOSR Journal of Dental and Medical Sciences.2015;14:27-33.

[18]. Shukla Y, Gupta P, Tiwari R, Kasar PK. Uncorrected refractive error in schoolchildren at Jabalpur district of Madhya Pradesh. Int J Med Sci Public Health 2016;5:764-8.
[19]. Sandip Das S and Bhavya M. Prevalence Of Refractive Errors In 10 - 16 Years Of Students In Eastern Bangalore, India. Int. J. Adv. Res. 2019; 7(4):35-40.

How to cite this article: $\mathrm{H}$. Siddesh Kumar, Srividya R. PREVALENCE AND EVALUATION OF REFRACTIVE ERRORS IN CHILDREN BETWEEN THE AGES 10-15 YEARS IN RIMS TEACHING HOSPITAL RAICHUR. Int J Intg Med Sci 2019;6(4):812-816. DOI: 10.16965/ijims.2019.112

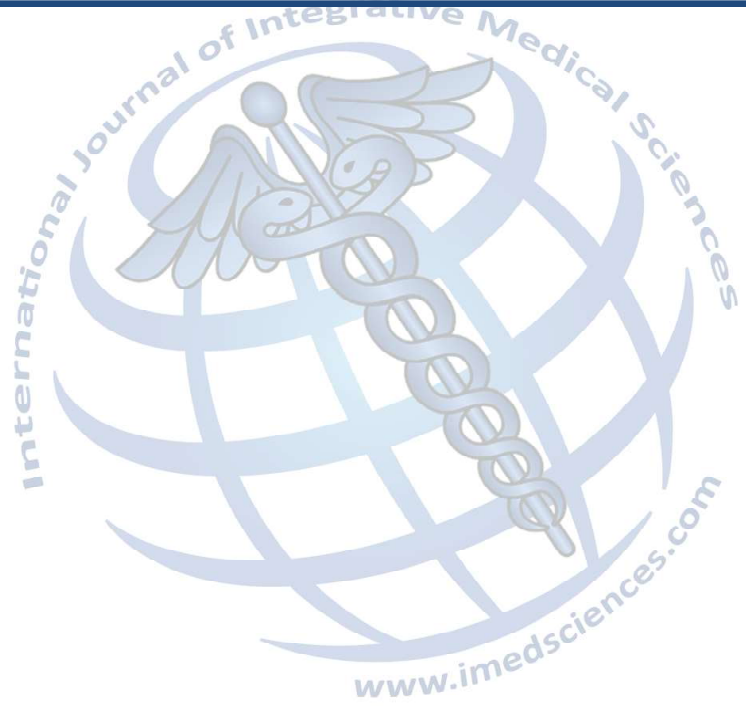

